\title{
The Factors of Trust and Perceived Usefulness, for the Satisfaction of Piraeus Bank I-Banking Customers, Economic Analysis and Econometric Approach
}

\author{
Zoyros Chrisovalantis ${ }^{1}$, Spinthiropoulos Konstantinos ${ }^{2, *}$ \\ ${ }^{1} \mathrm{MSc}$ in Banking - Hellenic Open University, Veria, 59100, Greece \\ ${ }^{2}$ Spinthiropoulos Konstantinos, Department of Accounting and Finance, Technological Educational Institute of Western Macedonia, \\ Kozani, 50100, Greece \\ *Corresponding Author: spinthiropoulos_k@yahoo.gr
}

Copyright (C) 2014 Horizon Research Publishing All rights reserved.

\begin{abstract}
We are living in Digital World and the Digital Revolution brings New Technologies at a very rabid pace. These amazing pace increased rapidly the speed of transmission of information via the internet. The Banking sector could not stay away from these technological changes . All over the world banking transaction were realized by the use of new technologies. The new technologies penetrations into the banking sector and the Internet banking use have continually marked an upward movement. Targeting to adopt and use the Internet Banking of Piraeus Bank, the customers demands should be met through the services. This paper focuses on the factors of service quality of Piraeus Bank and their impact on customer's satisfaction. The customer satisfaction is proportionally related to the Internet Banking services quality. In the framework of this research, based on the questionnaires, the economic analysis and the econometric approach, it is obviously substantiated that the factors, Trust and Perceived usefulness, are main to the high quality services provision and the customers are satisfied as far as these factors reach the high quality and meet their expectations.
\end{abstract}

Keywords Internet Banking, Winbank, Service Quality, Customer Satisfaction, Trust, Perceived Usefulness, Enrollment Rate Of New Customers

\section{Introduction}

In the frames of a digital economy, the internet has a dominant role in all activities. Next to this, the Internet Banking is a main sector of Bank services. The modern digital era of the internet and the rapid growth of users have led banks to invest in new technologies and, particularly, in the provision of electronic services in order to fully respond to customer requirements. Speaking specifically, in this research, we will study on an exclusive Greek Bank which activates in the frames of wide economic depression, since 2008 and after. So taking this into account, it is a matter of major worthiness to focus on the private Greek Bank function and the Internet banking contribution to its development, despite the hard economic status in Greece. So, focusing on Piraeus Bank due to the international awards and its innovation regarding the Greek e-banking and its great market proportion that is possessed since 2000 since today in Greece. Additionally, our main goal is to indicate that the Greek Private Bank Sector represents the basic exit tool of the economic crisis and depression.

In the frames of the current exceptional competitive environment, the services that should be provided by a bank to the customers, old and new ones, have to be of high quality and always higher than the customer demands and never lower of their expectations (Mefford, R. N., 1993, p. 405). Furthermore loyal customers are the ones who realize recurring transactions and purchases for a long period of time that they make their profit-making clients (Mols, N. P., 1998, p. 334). Most of the Banks, have invested on the internet banking based on the fact that the transactions in the future will be through Internet. Their digital platforms designed to cover the entire spectrum of customers, individuals, small and large businesses (Greek Union of Banks, 2003). The use of the internet by banks and the integrated provision of electronic services changed the cost functions and bank transactions.

\section{Overview}

In this frames, many researchers have commented on internet banking. We make reference to (Jun, \& Cai, 2001), (Aladwani, 2001, p. 214), (Liao \& Cheung, 2002) and (Jayawardhena \& Foley, 2000). Researchers, such as (Sathye, 1999, p.327), came to the conclusion that the factors, "the difficulty of use" and "the electronic transactions security" influence the Australian users, not to adopt the use of 
Internet Banking. Jayawardhena \& Foley (2000), suggested specific features of Internet Banking websites claiming that are of crucial importance concerning the customer satisfaction:

The speed to download 2.Content 3.Design 4.Interactivity 5.Navigation 6.Security.

The key - point for the banks to shill more customers through the online service is not only the Internet attraction but also the offered products to the clients (Dixon, 1999, p.13).

Though, some researchers supported that the 87 percent of the Internet banking customer base demands to have a variety of economic transactions in a place, (called "one stop shopping") especially on accounts payments electronically and automatically, the projection of the bank monthly statements and the stock market and the insurance (Latimore et al., 2000).

The service quality could be related to the customers' total evaluation with regard to electronic services provision in a virtual market (Santos, 2003, p. 235). Since the customers are able to have access to the bank or company website of different world places and to compare the company's or bank's services to services of other companies or banks, this makes us conclude that this constitutes one of the main factors of the advancement of the electronic services quality.

Taking into account our inferences, we strongly believe that the service quality is one of the most significant factors targeting the customers' satisfaction. Obviously, the services quality and the customers' satisfaction are highly connected. The customer satisfaction could be ensured by the high quality of products and services provision. Satisfaction is a psychological situation that is ensued by a procedure of emotional and cognitive evaluation" (Oliver, 1981, p. 31). This was substantiated and verified by Bearden \& Teel, 1983.

A research by Cronin and Taylor (1992) argued that the satisfaction has indirect effect on the customers' and Fornell et al., (1996), pinpointed that the satisfaction is important and shows the customer intention to continue on buying. Next to this, another researcher such us Doll and Torkzadeh (1988), proposed five characteristics that influence the user satisfaction quality:

1.Content 2. Accuracy 3. Format 4. Ease of use and 5. Timeliness

These five dimensions could be an integral part of the Internet Banking quality systems construction. The elements, concerning the Internet Banking, credibility and validity of services were well documented in other studies such as the Torkzadeh and Doll (1991).

In order to show basic features of the services quality that have a remarkable impact on the customer's perception with reference to a more general services quality (Parasuraman et al., 1985), (Parasuraman et al., 1988), conducted recognized researches. They initially found ten factors that determine the services quality that are based on a course of studies on groups via interviews. They mention that these factors were:
1. Tangibles
2.Reliability
3.Responsiveness

\section{Competency 5. Courtesy}

6. Communication 7.Credibility 8.Security 9.Access 10.Understanding the customer.

With the use of factor analysis (Parasuraman et al., 1988) enlisted these ten factors to five. These five factors were the following:

1. Tangibles 2.Reliability 3.Responsiveness 4.Assurance and 5.Empathy

The results of their research refer to the development of SERVQUAL, a research tool of 22 points for services quality measurement. The SERVQUAL has widely applied for the services quality measurement of the several organizations of services provision, including and the banks (Cowling \& Newman, 1995). However as Johnston (1995) reported the SERVQUAL, "has unfavorably criticized by other scientists" (p. 62).

\section{Methodology}

The current research has been realized targeting to study the users percentage and their satisfaction, by the Internet Banking of Piraeus Bank. The scope of this study is to find the role of the factors "trust" and "perceived usefulness" in the improvement of internet banking transactions. Our intention was to testify that the Internet Banking assisted in bank transactions advancement via the customers' satisfaction by the Service Quality and the importance of the factors trust and perceived usefulness of the customer. For the purpose of an effective issue examination, it was analyzed in the following researching goals:

To become aware of the people' s percentage that uses the service

To recognize the influence of trust to the users satisfaction issue

The significance of perceived usefulness

Their satisfaction ascertainment with regard to the Internet Banking services quality using economic analysis and econometric approach.

The crucial part of Internet Banking in the improvement of banking transactions.

Everyone participated in this research is customer of the Piraeus Bank who uses, at least, personal computer and alternative networks for his service. In this study, a great attempt takes place to register the perceptions, the believes and the preferences of the above groups concerning the Internet Banking. The data selection was realized by the use of a structured questionnaire which was distributed in printed and electronic form and was formed so as the crucial questions about the Internet Banking of Piraeus Bank to be answered in the biggest possible degree. Following to this, we will attempt an econometrical approach of the issue, using econometrical methods in order to substantiate if the dependent variable route could be explained and in what percentage of the independent variables of the function that we will establish.

Our main consideration of approaching this issue 
economically and econometrically is obvious. However, we should make reference to the fact that the questionnaires, their form and method will be analyzed next, and the choice of the specific Bank is not random. The Bank has been chosen for specific reasons. In this frameworks, we did not proceed to analyze more banks since we took into account that this would lead to false conclusions due to the Greek economic crisis and the previous and current difficult economic status (recapitalization need) of the Banks in Greece. Then, we had the intention to work on a self-inclusive study of the relevant bank and not of any others simultaneously, targeting to avoid misquoting the results.

The questionnaire that we used was structured and easily perceptible to the respondents. Closed type questions and scale questions are included in this questionnaire. Scale questions based on the Likert scale. The Likert scale is rather plain and is applied for the attitudes measurement. It is consisted of a number scale from 1 to 7 . On the scale edges we meet opposites' attitudes, when in the middle the attitude is neutral. Par example, if a fact is of low importance, it will take the grade 1 of the scale, in the middle of the scale the fact is characterized as neutral, when on the other edge scores 7 and this fact is characterized of great significance.

As it is known (Parasuraman A., Valarie A. Zeithaml and Leonard L. Berry, 1985) and (Parasuraman A., Valarie A. Zeithaml and Leonard L. Berry, 1988) used that scale in the service provision quality model, Servqual (abbreviation of the words Service Quality), but also Bahia and Nantel (2000), used it in their model BSQ (Bank Service Quality).

In the sample, about 1000 individuals were participated, older than 18 years old that had access to the banking transactions realization. The sample should have been defined so as to be representative. For this reason, customers of Piraeus Bank have been chosen and use the Internet Banking in the smallest possible degree. As far as the population is concerned, a random sample was selected by the usual sampling method. The population is characterized of the respective homogeneity, consequently the 1000 customers sample is considered satisfactory.

\section{Empirical Results and Analysis}

Starting the analysis of the results of this research, initially we describe some demographic information, for the sample of customers that took part. We used graphs and charts, trying to outline the profile of their demographic characteristics.

Figure 1, illustrates the composition of the sample on the basis of gender. In our survey took place 1000 Piraeus Bank clients, of which $62 \%$ is men and $38 \%$ is women.

As far as the age composition is concerned, as it is represented in figure 2, a relative consistency is noted in the sample percentages, verifying that the customers who use the alternative networks, they have been already of all ages. Speaking specifically, regarding the ages between 15-20 years old, just a small sample of $1 \%$ uses the alternative networks .This fact is completely logical as long as the younger people do not usually handle banking cases.

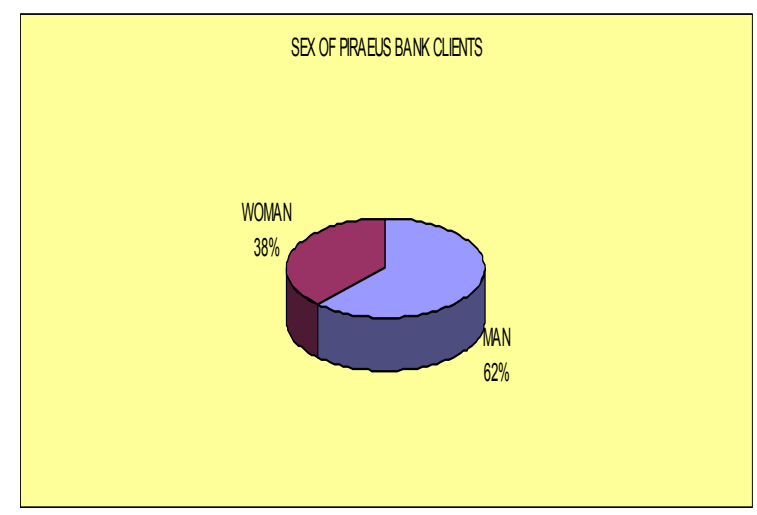

Figure 1. Gender of Piraeus Bank Customers

The majority participants' ages are from 26 to 45 and up years old. This percentage reaches the $20 \%$ in the ages of 26 -30 and $31-35$ years old, when in the ages of 36 to 40 years old, reaches the $21 \%$. The percentage, in the ages of $41-45$ reaches the $15 \%$, while in the ages 45 and up comes up to $18 \%$. Thus, it is remarked, based on the available data, that the biggest participants' ratio refers to the ages between 26 to 65 years old that are considered to be as the most productive group regarding the age.

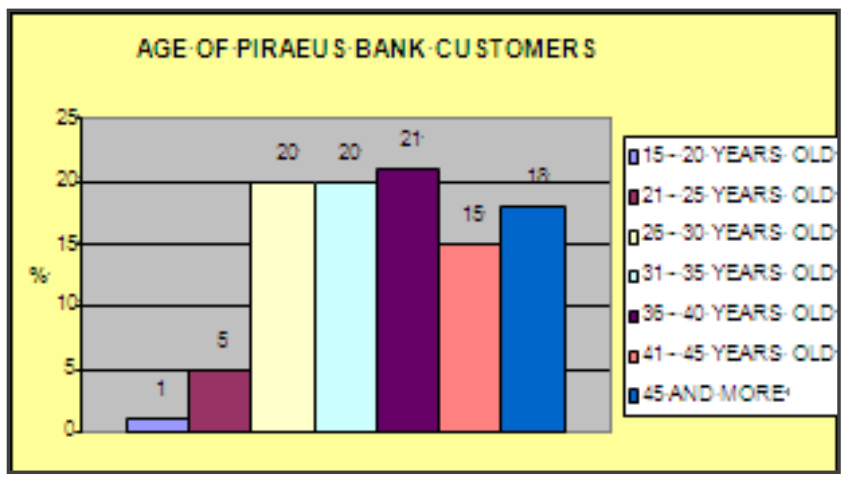

Figure 2. Age of Piraeus Bank Customers

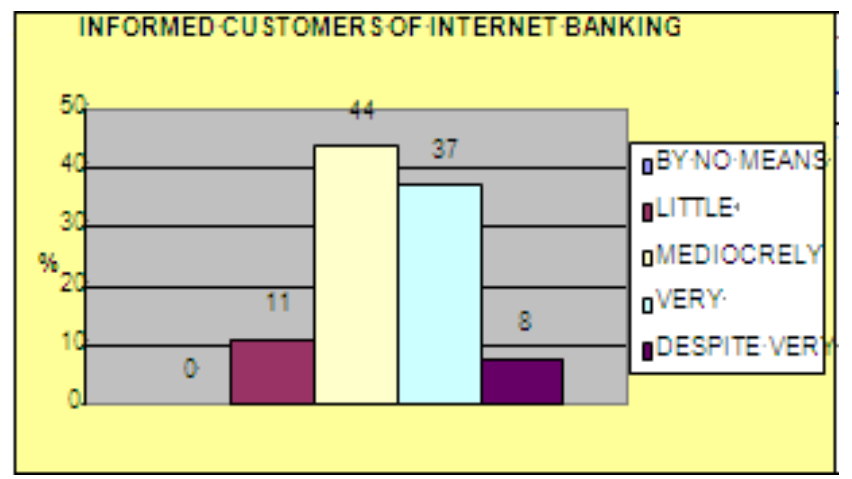

Figure 3. Informed Internet Banking Customers of Piraeus Bank

In the question, regarding the customers' level of information referring to the Internet Banking, the answers 
underline that the biggest percentage is covered by the customers that are medium and well informed. In particular, as it shown in figure 3 , the $11 \%$ of the asked people answered that has low information, when the $44 \%$ is medium informed. The $37 \%$ has good information and finally the $8 \%$ claimed that it is very well informed.

The answers, concerning the question about the applied services, are depicted in figure 4 . The biggest percentage refers to two specific services, the accounts administration and the payments/transfers. Speaking in specific, the $38 \%$ manages its accounts through Internet Banking, while the $42 \%$ pays the accounts and realizes cash transfers. The $12 \%$ sends remittances and the smallest percentage is covered by the financial transactions and the products applies, about $4 \%$ each of them.

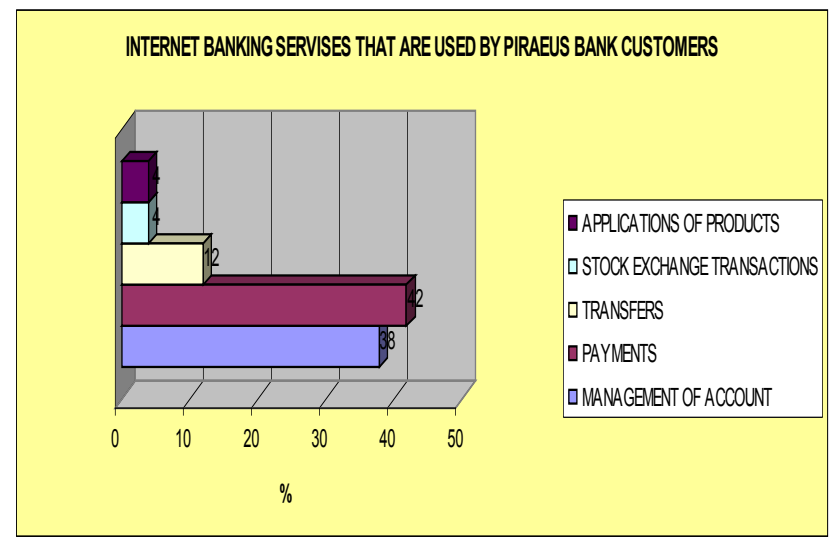

Figure 4. Internet Banking Services that are Used by Piraeus Customers

As far as the Internet Banking frequency use is concerned, as it is shown in figure 5, it varies among the answers of seldom, often and very often. Specifically, the seldom answer reaches the percentages of $11 \%$, when the $25 \%$ is reached by the often answer and the $23 \%$ belongs to answer of very often, and finally the percentage of $41 \%$ claims that uses Internet Banking, daily. So we come to the conclusion that over the $50 \%$ of the customers uses the services often and very often.

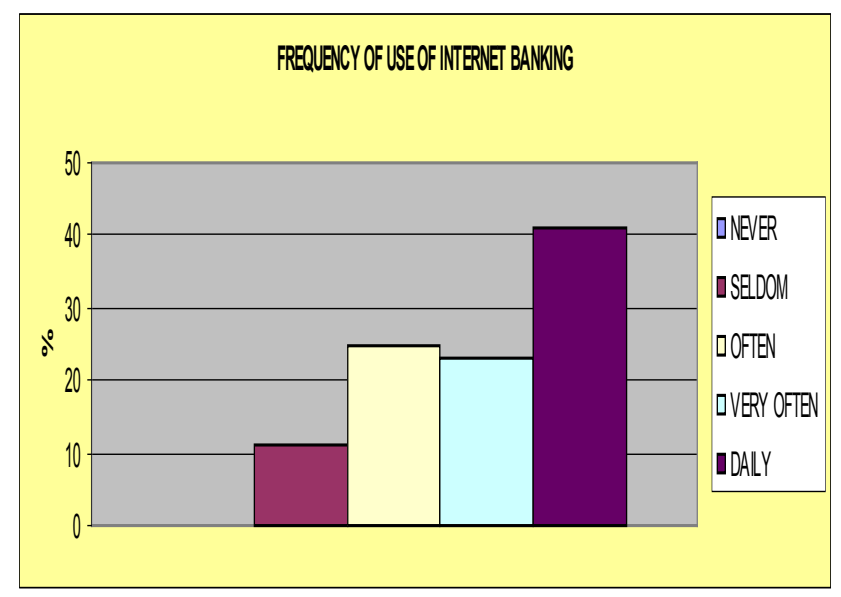

Figure 5. Frequency of Use of Internet Banking by Piraeus Bank
Possibly, one of the most crucial questions, according to our opinion, which was set in our search questionnaires, were the users satisfaction by the internet Banking services applying. The answers have a significant part, taking into account the importance of satisfaction factor regarding the Internet Banking. The biggest customers satisfaction is, the more transactions will be realized.

The biggest percentage, as it is obvious in figure 6 , is the $54 \%$ of the customers who claim that are very satisfied. The $28 \%$ follows that represents the answer medium satisfied and the $17 \%$ refers to the very satisfied customers. There is also a very low percentage of $1 \%$ that shows little satisfaction.

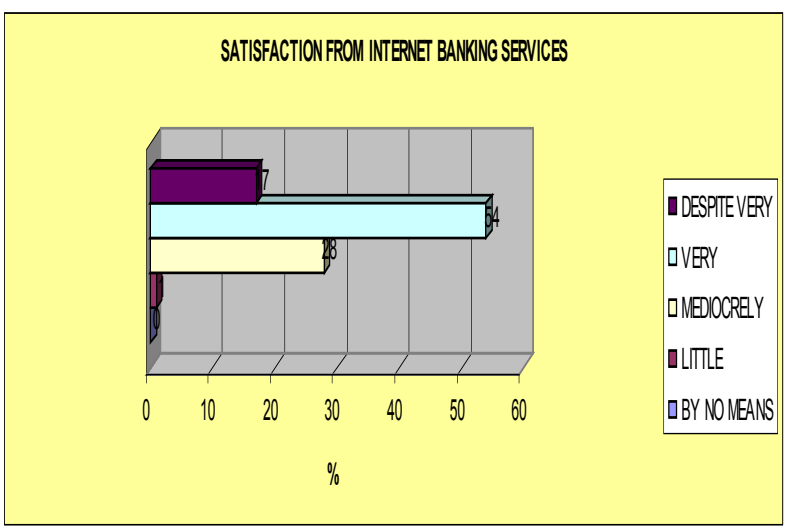

Figure 6. Satisfaction from Internet Banking Services

As it is shown in figure 7, we analyze the factor of customer's trust in electronic services of Piraeus Bank. Whether that is, users trust the Internet Banking, to make their transactions through Winbank. As shown there are a $2 \%$ of all respondents who answered while a moderate $6 \%$ agree while. The $19 \%$ said they agree, $42 \%$ said they agree and that has much confidence in online services Winbank, and a rate of approximately $31 \%$ responded that it agrees completely. We conclude that nearly three out of four users are satisfied and that they trust the Internet Banking services.

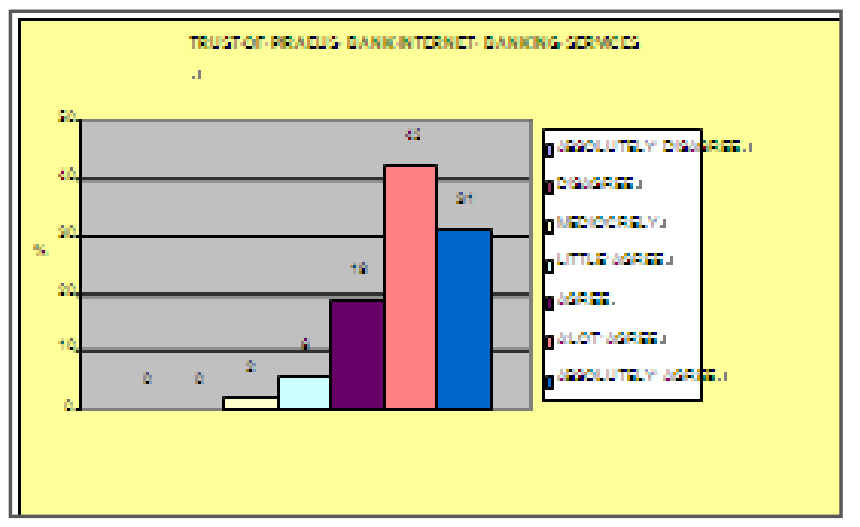

Figure 7. Trust of Piraeus Bank Internet Banking Services

As it is shown in figure 8 , only the $2 \%$ of the customers answered that perceived usefulness is very little. $6 \%$ answered little and $10 \%$ answered mediocrely. Customers consider that perceived usefulness is important in $27 \%, 32 \%$ 
very important and $23 \%$ despite very important. It is obvious from the answers that this factor is very important for a quality service and the satisfaction of Piraeus Bank, Internet Banking.

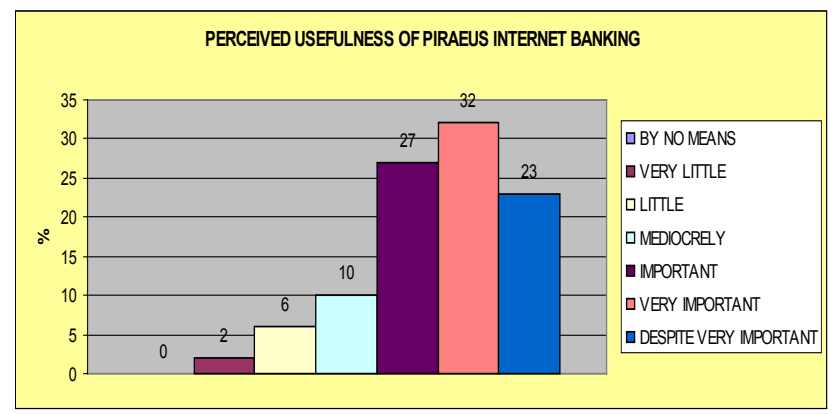

Figure 8. Perceived Usefulness of Piraeus Bank Internet Banking

Table 1. Enrollment Rate Of New Customers Of Piraeus Bank Internet Banking

\begin{tabular}{|c|c|}
\hline YEAR & $\begin{array}{c}\text { ENROLLMENT RATE OF NEW } \\
\text { CUSTOMERS OF PIRAEUS BANK } \\
\text { INTERNET BANKING }\end{array}$ \\
\hline 2003 & $16 \%$ \\
\hline 2004 & *Not Available \\
\hline 2005 & $38 \%$ \\
\hline 2006 & $30 \%$ \\
\hline 2007 & *Not Available \\
\hline 2008 & $33 \%$ \\
\hline 2009 & $24 \%$ \\
\hline 2010 & $21 \%$ \\
\hline 2011 & $20 \%$ \\
\hline
\end{tabular}

Additionally, we studied on the case of enrollment rate of new customers through Piraeus Bank Internet Banking. The examined time-framework, as it is pinpointed in Table 1, refers to years from 2003 to 2011 . We observe that the every year variation is positive. Namely in percentages, every year the enrollment rate of new customers Piraeus Bank Internet Banking is increasing. This fact is explained, in our view, by the increase of trust, perceived usefulness and the Piraeus Internet Banking customers' satisfaction.

\section{Economic Analysis and Econometric Approach}

Goaling to establish the impact of the Trust and Perceived Usefulness variables to the Satisfaction of Customers using internet banking, we have decided to apply the econometric methods. Our purpose was to study the influence of the independent variables of Trust and Perceived Usefulness, on the route of dependent variable (speaking in percentage) Satisfaction of Customers using internet banking.

The form of regression will be used in order to explain the relationship between dependent and independent variables is:

$$
\left.Y_{i}=b_{0}+b_{1} X_{1 i}+b_{2} X_{2 i}+\ldots \ldots+b_{k} X_{k i}+u_{i} \quad \text { (equation } 1\right)
$$

where $\mathrm{i}=1,2 \ldots \mathrm{n}$ comments the coefficients $b_{1}, b_{2}, \ldots, b_{k}$ quantify the effects of the corresponding variables $X_{1}, X_{2}, \ldots, X_{k}$. The coefficients version $b_{1}, b_{2}, \ldots ., b_{k}$ diversifies from the version $b_{1}$ in the frames of the plain regression, as long as the coefficient $b_{j}$ represents the variation in the average price of the $\mathrm{Y}$ dependent variable, when the variable that goes with the $X_{j}$, is increased at one point and the other variables remain stable .

Finally, the parameter $b_{0}$ is the so-called constant regression coefficients and $X_{k}$ are the independent variables (explanatory) regression and regression error known as ei (regression error). If the level of materiality in accounting regressions is less than 0.10 then the parameter is useful in model, which means that statistically significant.

As we note from Table 2 it is observed that there is no correlation between the variable group Satisfaction and Trust respectively whenever we move and the subsequent variables of the model. Also in Table 2 we see that the groups of variable PerUsefulness not observed correlation whenever we can use the groups of this variable in order to check the connection with the dependent variable satisfaction. 
Table 2. Correlogram of Residuals

\begin{tabular}{|c|c|c|c|c|c|c|}
\hline Autocorrelation & Partial Correlation & & $\mathrm{AC}$ & PAC & Q-Stat & Prob \\
\hline.$|\quad|$ &.$|\quad|$ & 1 & -0.013 & -0.013 & 0.0166 & 0.897 \\
\hline . 1 & .. $\quad \mid$ & 2 & 0.055 & 0.055 & 0.3328 & 0.847 \\
\hline$. l^{*} \quad \mid$ & $. .^{*} \quad \mid$ & 3 & 0.203 & 0.205 & 4.6468 & 0.200 \\
\hline.$|\quad|$ &.$|\quad|$ & 4 & -0.047 & -0.045 & 4.8856 & 0.299 \\
\hline$. \quad \mid$ & . $\quad \mid$ & 5 & 0.025 & 0.001 & 4.9543 & 0.421 \\
\hline.$|\quad|$ & .. $\quad \mid$ & 6 & 0.045 & 0.010 & 5.1742 & 0.522 \\
\hline$. .^{*} \quad \mid$ & $.1^{*} \quad \mid$ & 7 & 0.135 & 0.161 & 7.1775 & 0.411 \\
\hline$*|. \quad|$ & $*|. \quad|$ & 8 & -0.074 & -0.087 & 7.7889 & 0.454 \\
\hline.$|\quad|$ &.$|\quad|$ & 9 & -0.013 & -0.046 & 7.8089 & 0.554 \\
\hline.$|\quad|$ & $*|. \quad|$ & 10 & -0.065 & -0.122 & 8.2894 & 0.601 \\
\hline$*|. \quad|$ & $*|. \quad|$ & 11 & -0.119 & -0.072 & 9.9049 & 0.539 \\
\hline.$|\quad|$ & $.1 . \quad \mid$ & 12 & -0.057 & -0.058 & 10.280 & 0.591 \\
\hline.$|\quad|$ & .1. $\quad \mid$ & 13 & -0.002 & 0.038 & 10.281 & 0.671 \\
\hline$*|. \quad|$ & .. $\quad \mid$ & 14 & -0.071 & -0.059 & 10.879 & 0.695 \\
\hline$*|. \quad|$ & $*|. \quad|$ & 15 & -0.135 & -0.110 & 13.062 & 0.598 \\
\hline.$|\quad|$ &.$|\quad|$ & 16 & -0.012 & -0.015 & 13.081 & 0.667 \\
\hline$*|. \quad|$ & .|. $\quad \mid$ & 17 & -0.092 & -0.021 & 14.113 & 0.659 \\
\hline$*|. \quad|$ & $*|. \quad|$ & 18 & -0.134 & -0.084 & 16.353 & 0.568 \\
\hline.$|\quad|$ & $.1 . \quad \mid$ & 19 & -0.038 & -0.056 & 16.535 & 0.621 \\
\hline.$|\quad|$ & .|. | & 20 & -0.009 & 0.004 & 16.545 & 0.682 \\
\hline | &. $\mid$ & 21 & -0.047 & -0.001 & 16.836 & 0.721 \\
\hline $.1 . \quad \mid$ &. $\mid$ & 22 & 0.000 & 0.016 & 16.836 & 0.772 \\
\hline.$|\quad|$ &.$|\quad|$ & 23 & 0.050 & 0.036 & 17.165 & 0.801 \\
\hline | & $.\left.\right|^{*} \quad \mid$ & 24 & 0.051 & 0.081 & 17.509 & 0.826 \\
\hline. $\mid$ &. $\mid$ & 25 & 0.050 & 0.046 & 17.850 & 0.849 \\
\hline.$|\quad|$ &. $\mid$ & 26 & 0.025 & -0.024 & 17.939 & 0.878 \\
\hline $.1 . \quad \mid$ & $*|. \quad|$ & 27 & -0.031 & -0.095 & 18.072 & 0.901 \\
\hline. $\mid$ & $*|. \quad|$ & 28 & -0.020 & -0.068 & 18.131 & 0.923 \\
\hline. $\mid$ & $*|. \quad|$ & 29 & -0.034 & -0.092 & 18.297 & 0.938 \\
\hline.$|\quad|$ & $*|. \quad|$ & 30 & -0.039 & -0.076 & 18.517 & 0.950 \\
\hline$. .^{*} \quad \mid$ & $. l^{*} \quad \mid$ & 31 & 0.095 & 0.084 & 19.854 & 0.939 \\
\hline.$|\quad|$ &. $\mid$ & 32 & -0.012 & -0.012 & 19.874 & 0.953 \\
\hline$.\left.\right|^{*} \quad \mid$ & $.\left.\right|^{*} \quad \mid$ & 33 & 0.105 & 0.119 & 21.557 & 0.937 \\
\hline.$|\quad|$ &. $\mid$ & 34 & 0.007 & 0.010 & 21.565 & 0.952 \\
\hline$*|. \quad|$ & $*|. \quad|$ & 35 & -0.092 & -0.070 & 22.904 & 0.942 \\
\hline.$|\quad|$ & $*|. \quad|$ & 36 & -0.007 & -0.075 & 22.911 & 0.956 \\
\hline
\end{tabular}

Table 3. 1st Regression Results

\begin{tabular}{|c|c|}
\hline Observations:1000 & \\
\hline $\begin{array}{c}\text { Dependent Variable: Satisfaction (group variable) } \\
\text { Independent Variables: Content and Understanding the } \\
\text { customer }\end{array}$ & Explain: Satisfaction of Customers using internet banking \\
\hline R-squared & 0.62 \\
\hline Durbin-Watson Stat & 1.84 \\
\hline Prob (F-statistic) & 0.000117 \\
\hline C Coefficient & 2.106 \\
\hline Trust Coefficient & 0.233 \\
\hline PerUsefulness Coefficient & 0.099 \\
\hline
\end{tabular}


Taking into account the table 3, we observe that the two model variables do not show autocorrelation issue of a degree having the $\mathrm{DW}=1.84$ (Accepted limit $1.82<\mathrm{DW}<2.04)$ rate. In fact, we could say that the DW is perfect for our sample. (Tsanaktsidis et al, 2012) conducted the statistical analysis of the series by using irregular undated data that led them to the use of linear regression. Following, the above researchers and having of course irregular undated data like them, we conclude that the variable "customer satisfaction" related positively with the independent variables "trust" and "perceived usefulness". It is natural and scientifically acceptable, that two variables not auto correlated, to have impact on the each other's route.Speaking specifically, based on the $\mathrm{R}^{2}$ the approximately $62 \%$ of the dependant variable variability is attributed by the regression. The $38 \%$ residual is preceded by foreign factors and are not included in this question model.

$$
\text { Satisfaction }=0.008+0.78 \text { Trust }+0.46 \text { PerUsefulness (Equation 2.) }
$$

So the above regression equation (equation2) has correct signals. We expected that the dependent variable called "Customers satisfaction" and the independent variables "trust" and "perceived usefulness" to have a positive connection. In other words, the "trust" and "perceived usefulness", is analogue to the customers' satisfaction.

So, we notice that the P-value is equal to 0,000117 that shows a statistical importance to $1 \%(>0,000)$. This leads to the conclusion that the independent variables "trust" and "perceived usefulness" is statistically significant since probability for Trust is equal to 0.0001 ( under $1 \%$ ) and for PerUsefulness is equal to 0.10 (equal to $10 \%$ ). If we accept the $10 \%$ significant, this means that our model independent variables have positive impact on the Satisfaction dependent variable route.

\section{Conclusions}

Accordingly, in our research we have proceeded to a thorough analysis of the bibliography, with reference to the e-banking factors which were used in previous studies. Next to this, we have come to the conclusion that the applied factors of the specific research are capable of showing their impact on the e-banking customers' satisfaction at the researching years.

Apart from the questionnaires analysis, we decided to proceed on or research realizing an econometric approach. Then, the econometric approach studies the possible connection between the applied variables. Several researchers use qualitative questionnaire data in order to underline the variables connection. It is not necessary to make specific reference to previous studies, since in our days the econometric approaches are not limited only to qualitative or quantitative ones, or primarily to economical and financial researches. Par example, Tsanaktsidis et al (2012), by applying a relevant method, attempted to establish the connection between the variables regarding the fluid fuels.

However, at this point, it is essential to mention that several researchers (Krishna Naik et al., 2010) proceeded to similar econometric tests targeting to testify the possible influence of Service Quality factor on satisfaction and they resulted in the $\mathrm{R}^{2}$ percentage test .

We have come to the conclusions that Piraeus Bank clients take seriously the factors of "trust" and "perceived usefulness". The percentage is relatively high $(=62 \%)$ and attention should be given to these factors in subsequent measurements. They indicate that the trust and perceived usefulness, have a great part in the Internet Banking customer's satisfaction. All parameters-variables, analyzed in tables and figures, lead to positive output regarding the future of Piraeus Bank Internet Banking.

Thus the econometric models use assists the researchers in defining specific results. In the current research, the econometric approach testified that the variables that improve Internet Banking transactions are positive and statistically significant and do not exhibit autocorrelation issues.

Thus, we have the indention of realizing the comparison of more Greek banks in a sequential publication of this research. It is our believe that the implementation of Greek banks recapitalization will provide us with secure conclusions based on their comparison.

\section{REFERENCES}

[1] Aladwani, A. M. (2001). Online banking: a field study of driver, development challenges, and expectations. International Journal of Information Management. 21, 213-225

[2] Bearden, W. O., \& Teel, J. E. (1983). Selected determinants of consumer satisfaction and complaint reports. Journal of Marketing Research, 20, 21-28

[3] Bahia, K., \& Nantel, J. (2000). A reliable and valid measurement scale for the perceived service quality of banks. International Journal of Bank Marketing, 18 (2), 84-91

[4] Cowling, A., \& Newman, K. (1995). TQM, service quality and human resources. (review of the book Banking on people), 24 (7), 25-40

[5] Cronin, J., \& Taylor, S.,(1992). Measuring Service Quality: A Reexamination and Extension, Journal of Marketing, 56 (3): 55-68

[6] Dixon, M. (1999). Com madness: 9 must - know tips for putting your bank online, America's Community Bankers, 8 (6), 12-15

[7] Doll, W. J., \& Torkzadeh, G. (1988). The measurement of end-user computing satisfaction. MIS Quarterly (12:2), June, 259-274

[8] Fornell, C., Johnson, M., Anderson, E. W., Cha, J. \& Bryant, 
B. (1996). The American customer satisfaction index: nature, purpose, and findings. Journal of Marketing, 60, 7-18

[9] Greek Union of Banks. (2003). Repercussions of Internet in the operation and profitability of enterprises: Profits from the use of services of electronic banking (3rd ed.). Athens, DC: Author.

[10] Jayawardhena, C., \& Foley, P. (2000). Changes in the banking sector - the case of Internet Banking in Uk. Electronic Networking Applications and Policy, 10 (1), 19-30

[11] Johnston, R. (1995). The determinants of service quality: satisfiers and disatisfiers", International Journal of service Industry Management, 6 (5), 53-71

[12] Jun, M., \& Cai, S. (2001). The key determinants of Internet bancaire service qality: content analysis. The International Journal of Bank Marketing, 19, 7

[13] Krishna Naik, C., Swapna Bhargavi Gantasala, Prabhakar Gantasala, V. (2010). Service Quality (Servqual) and its Effect on Customer atisfaction in Retailing. European Journal of Social Sciences, 16 (2), 231-243

[14] Latimore, D., Watson, I., \& Maver, C. (2000). 3.300 Internet Users tell us what they want from retail financial services, The customer speaks. Retrieved from http://www.mainspring.com/research/document/view/1,2099 ,1215,00.html

[15] Liao, Z., \& Cheung, M. T. (2002). Internet based e-banking and consumer attitudes: An empirical study. Journal of Information and Management, 39, 283-295

[16] Mefford, R. N. (1993). Improving service quality: learning from manufacturing. International Journal of Production Economics, 30, 399-413
[17] Mols, N.P. (1998). The Internet and the banks strategic distribution channel decisions. Journal of Internet Research, $8,331-337$

[18] Oliver, R. L. (1981). Measurement and Evaluation of Satisfaction Processes in Retail Settings. Journal of Retailing, $57,25-48$

[19] Parasuraman, A., Zeithaml, V. A., \& Berry, L. L., (1985). A conceptual model of service quality and it's implications for feature research. Journal of Marketing, 49, 41-50

[20] Parasuraman, A., Zeithaml, V. A., \& Berry, L. L., (1988). SERVQUAL: A multi item scale for measuring consumer perception of service quality. Journal of retailing, 64, 12-40

[21] Santos, J. (2003). E-service Quality: A Model of Virtual Service Quality Dimensions. Managing Service Quality, 13 (3), 233-246

[22] Sathye, M. (1999). Adoption of Internet Banking by Australian consumers: an empirical investigation. International Journal of bank Marketing, 17 (7), 324-334

[23] Torkzadeh, G., \& Doll, W. J., (1991). Test - retest reliability of the end-user computing satisfaction instrument. Journal of Decisions Sciences, 22, 26-37

[24] Tsanaktsidis C. G., Christidis S. G., Spinthiropoulos K. G., \& Tzilantonis G.T., (2012). Exporting a Regression Equation for the Determination of Conductivity in Blends of Diesel Fuel with Biodiesel. Proceedings from CISSE '12: International Joint Conferences on Computer, Information, Systems Sciences, and Engineering. University of Bridgeport, USA 